09.1

\title{
Рентгенолюминесценция нитевидных микроструктур ZnO
}

\author{
(C) А.Э. Муслимов ${ }^{1}$, И.Д. Веневцев ${ }^{2}$, Л.А. Задорожная ${ }^{1}$, П.А. Родный ${ }^{2}$, В.М. Каневский ${ }^{1}$ \\ ${ }^{1}$ Федеральный научно-исследовательский центр „Кристаллография и фотоника“ РАН, \\ Москва, Россия \\ 2 Санкт-Петербургский политехнический университет Петра Великого, Санкт-Петербург, Россия \\ E-mail: amuslimov@mail.ru
}

Поступило в Редакцию 19 декабря 2019г.

В окончательной редакции 16 марта 2020 г.

Принято к публикации 20 апреля 2020г.

\begin{abstract}
Исследованы морфология, оптические и люминесцентные свойства ансамбля нитевидных микрокристаллов $\mathrm{ZnO}$ на сапфире, полученных методом газотранспортного синтеза из паров цинка и кислорода по механизму пар-жидкость-кристалл. Ансамбль сформирован одноосными микрокристаллитами $\mathrm{ZnO}$ двух морфологий: комбинация гексагональной призмы и монокристаллических микростержней. Коротковолновая граница прозрачности ансамбля вискерных микроструктур расположена в области длин волн $385-395 \mathrm{~nm}$. Полное пропускание образца в видимой и ближней инфракрасной области составляет порядка 10-20\% при толщине слоя порядка 15-18 $\mu \mathrm{m}$. Спектр рентгенолюминесценции представлен двумя полосами: интенсивной узкой экситонной с максимумом в области $388.3 \mathrm{~nm}$ и менее интенсивной (в 2.25 раза) широкой в области 430-600 nm. Постоянная времени затухания для экситонной люминесценции составляет порядка $1.1 \mathrm{~ns}$ (без учета ширины возбуждающего импульса), что получено для нелегированных микроструктур ZnO впервые.
\end{abstract}

Ключевые слова: $\mathrm{ZnO}$, микроструктуры, рентгенолюминесценция.

DOI: 10.21883/PJTF.2020.14.49667.18159

Ввод в действие современных ускорителей с высокой энергией и светимостью требует конструирования детекторов с улучшенными характеристиками в энергетическом, пространственном и временно́м разрешении. Не менее важными требованиями являются высокая надежность, радиационная стойкость, а также простота и дешевизна изготовления. Таким требованиям удовлетворяют сцинтилляционные счетчики, однако изготовить сцинтиллятор одновременно с относительно большим световыходом и малым временем отклика на данном этапе не удается.

В настоящее время наиболее перспективным материалом для применения в качестве сцинтиллятора считается ZnO, однако удовлетворительное для применения временно́е разрешение достигается только при использовании объемных кристаллов $\mathrm{ZnO}$ [1]. Дело в том, что в спектре излучения $\mathrm{ZnO}$ обычно присутствуют две компоненты излучения: экситонная люминесценция, находящаяся вблизи края фундаментального поглощения $(380-400 \mathrm{~nm})$, и зеленая люминесценция с максимумом в области 450-650 nm [2]. Экситонная люминесценция в $\mathrm{ZnO}$ имеет характерное время высвечивания менее $1 \mathrm{~ns}$ [3], что может быть использовано в сцинтилляционных счетчиках. Зеленая же люминесценция, источником которой являются дефекты кристаллической решетки $\mathrm{ZnO}[2,4]$, обладает характерным временем порядка $1 \mu \mathrm{s}$, хотя и гораздо бо́льшим световыходом. Объемные кристаллы ZnO, обладающие совершенной кристаллической структурой, демонстрируют преимущественно экситонную люминесценцию и применяются для регистрации гамма-квантов и рентгеновского излучения, для которых необходим довольно большой объем вещества. Однако имеющиеся на данный момент исследования $[5,6]$ показывают техническую сложность и дороговизну изготовления $\mathrm{ZnO}$ в форме монокристаллов. Альтернативой объемным кристаллам могут являться керамики, толстые (более $10 \mu \mathrm{m})$ пленки и ансамбли микрокристаллов $\mathrm{ZnO}$. Для достижения большой скорости регистрации зеленая компонента люминесценции в керамике $\mathrm{ZnO}$ может быть потушена посредством легирования оксида цинка трехвалентными ионами (Ga, In) [7]. Несмотря на превосходные сцинтилляционные характеристики оптической керамики $\mathrm{ZnO}$, представляется технологически сложным наносить ее непосредственно на детектор. В дополнение керамика имеет невысокую степень прозрачности к собственному излучению. В работе [8] с использованием методики магнетронного распыления с „неохлаждаемой ${ }^{\prime}$ мишени были получены и изучены толстые пленки $\mathrm{ZnO}$ с толщиной более $30 \mu \mathrm{m}$. По причине экстремально высокой скорости осаждения толстые пленки отличались высокой дефектностью и характеризовались только зеленой полосой люминесценции. Постростовый рекристаллизационный отжиг не способствовал ее подавлению. В связи с этим весьма перспективным представляется использование в качестве сцинтилляторов ансамблей нитевидных (вискерных) кристаллов $\mathrm{ZnO}$, формирующихся в процессе „самокаталитического“ роста по механизму пар-жидкость-кристалл (ПЖК). Они представляют собой высокоплотный массив одноосных монокристаллических микроструктур, осевое 
$a$

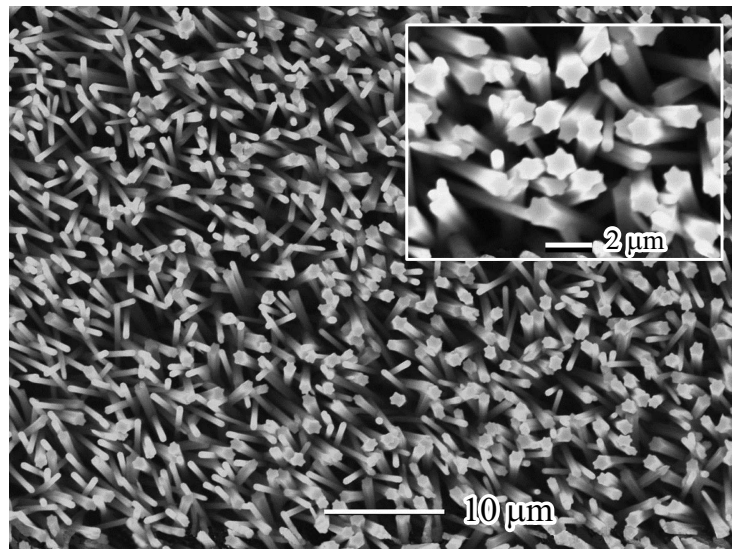

$b$

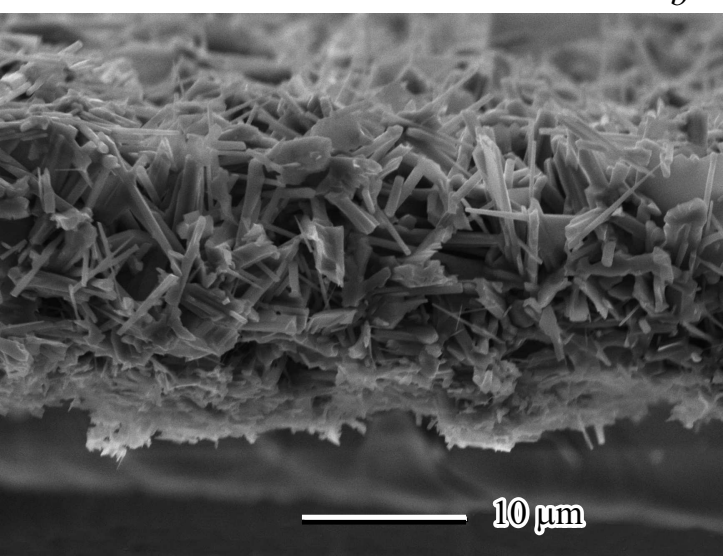

Рис. 1. Морфология $(a)$ и электронно-микроскопическое изображение поперечного среза $(b)$ ансамбля вискерных микрокристаллов $\mathrm{ZnO}$ на сапфире, выращенных при температуре $580^{\circ} \mathrm{C}$. Время синтеза $20 \mathrm{~min}$.

разупорядочение которых может увеличиваться со временем осаждения. В настоящей работе представлены результаты исследований морфологии, оптических и рентгенолюминесцентных свойств ансамбля нитевидных микрокристаллов оксида цинка на сапфире.

Массивы микрокристаллов оксида цинка вюрцитной структуры были выращены методом химического осаждения из газовой фазы из паров цинка и кислорода без использования катализатора по методике, описанной в работе [9]. В качестве подложек использовались пластины сапфира, двусторонне обработанные химикомеханическим способом. Процесс „самокаталитического“ роста был достигнут за счет механизма ПЖК, в котором роль металла-катализатора одномерного роста выполняли капли жидкого цинка. Такой „самокаталитический“ процесс обеспечивает возможность контролируемо осуществлять направленный рост микрокристаллов $\mathrm{ZnO}$, избегая при этом загрязнения примесью, и проводить процесс при более низкой температуре.

Микроскопические исследования осуществлялись на растровом электронном микроскопе Jeol Neoscope 2 (ЈСМ-6000). Средняя толщина слоя определялась при исследовании поперечных срезов образцов методом электронной микроскопии.

Измерения спектров рентгенолюминесценции (РЛ) проводились в геометрии „на отражение“ под непрерывным рентгеновским возбуждением $(40 \mathrm{kV}, 10 \mathrm{~mA}$, вольфрамовый анод). Для регистрации оптического излучения использовались монохроматор МДР-2 и система счета фотонов Hamamatsu H8259-01. Спектр излучения измерялся в диапазоне $350-650 \mathrm{~nm}$. При этом проводилась корректировка на спектральную чувствительность установки.

Спектры полного пропускания измерялись в диапазоне 350-1100 nm при помощи двухлучевого спектрофотометра SPECORD 200 PLUS, оборудованного интегрирующей сферой.
Исследования кинетики РЛ выполнялись в интегральном режиме, т.е. без выделения определенного спектрального диапазона, при импульсном рентгеновском возбуждении методом однофотонного счета при помощи установки, описанной в [10].

Все спектральные и кинетические исследования проводились при комнатной температуре.

Рассматривались массивы микрокристаллов $\mathrm{ZnO}$ двух морфологий: призматические (столбчатые, с постоянным сечением) и микростержни. На рис. 1, $a$ представлен ансамбль вискерных кристаллов $\mathrm{ZnO}$ на подложке сапфира с толщиной слоя порядка $15-18 \mu \mathrm{m}$ (рис. $1, b)$ и низкой степенью разупорядоченности. Согласно электронно-микроскопическим изображениям, имелось два типа одноосных микроструктур: изолированные, разориентированные относительно друг друга гексагональные призмы со средним диаметром 400-600 nm и микрокристаллические стержни с кристаллической огранкой со средним диаметром 100-150 nm. Разница в морфологии и диаметрах микрокристаллов объясняется условиями кристаллизации по механизму ПЖК.

По условиям проведения синтеза зона испарения цинка имеет бо́льшую температуру, чем зона роста. Поэтому первоначально в зоне роста происходит частичная конденсация металлического цинка с образованием на подложке массива капель жидкого Zn, которые являются основными центрами зарождения и ориентации микрокристаллитов.

Считается, что при механизме ПЖК диаметр растущего кристалла определяется размерами капли металлакатализатора. Спектр капель по размерам может быть довольно широким. Это зависит от температуры и, что особенно важно, от концентрации Zn в газовой фазе. Расстояния между каплями имеют величину порядка микрометров. Благодаря этому микрокристаллы разного диаметра растут практически в идентичных условиях.

Спектр РЛ (рис. 2) ансамбля вискерных кристаллов $\mathrm{ZnO}$ представлен двумя полосами: интенсивной узкой 


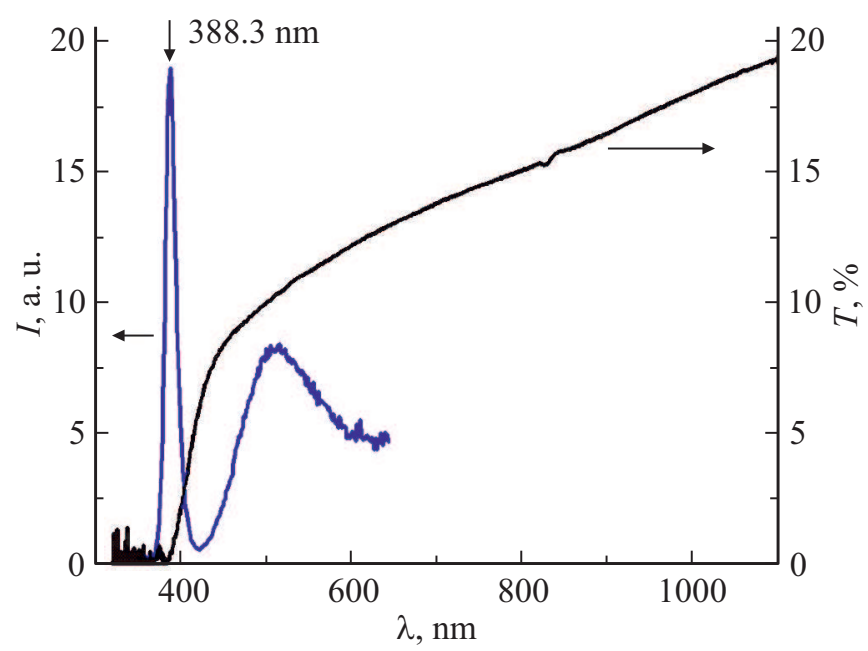

Рис. 2. Спектры РЛ и полного пропускания ансамбля вискерных микрокристаллов $\mathrm{ZnO}$.

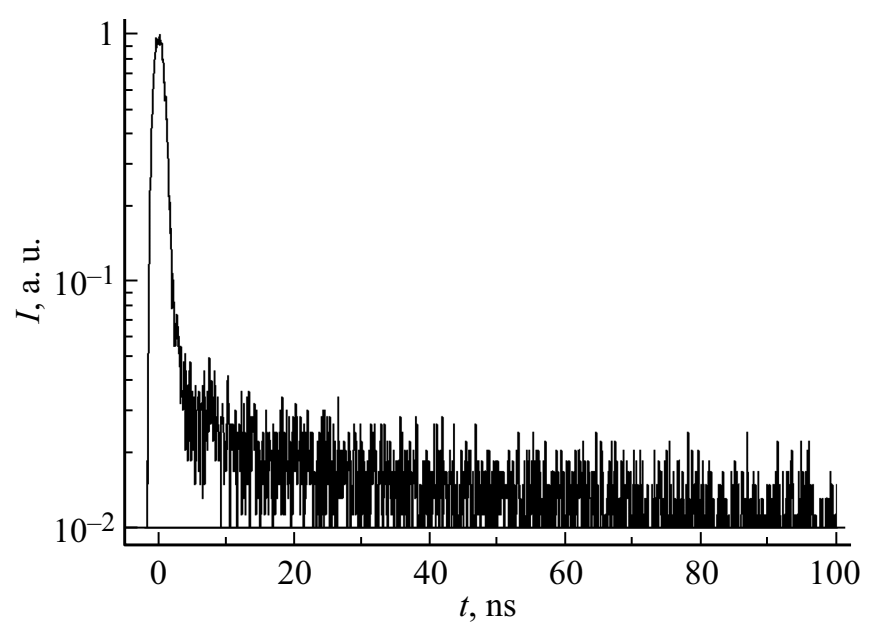

Рис. 3. Кинетика РЛ ансамбля вискерных микрокристаллов $\mathrm{ZnO}$.

экситонной с максимумом на длине волны $388.3 \mathrm{~nm}$ и менее интенсивной (в 2.25 раза) широкой в области 430-600 nm. Коротковолновая полоса расположена вблизи края фундаментального поглощения ZnO. Ее источником являются свободные экситоны, которые имеют энергию связи порядка $60 \mathrm{meV}$ и, как следствие, относительно стабильны при комнатной температуре [3]. Источником зеленой люминесценции на данный момент считаются собственные дефекты кристаллической решетки $\mathrm{ZnO}$, такие как вакансии кислорода $V_{\mathrm{O}}$ или кластеры, состоящие из вакансии $V_{\mathrm{O}}$ и межузельного иона цинка $\mathrm{Zn}_{i}[2,4]$. Полное пропускание образца (рис. 2) в видимой и ближней инфракрасной области составляет порядка 10-20\%. Низкая величина пропускания может быть обусловлена увеличенным расстоянием, которое проходит свет за счет диффузного рассеяния, и, следовательно, большей вероятностью поглощения. Коротковолновая граница прозрачности ансамбля ни- тевидных микроструктур расположена на длине волны $385 \mathrm{~nm}$. В длинноволновой области регистрируется нехарактерный для нелегированного $\mathrm{ZnO}$ плавный рост коэффициента пропускания [11]. Также была изучена кинетика РЛ (рис. 3). Поскольку измерения проводились в интегральном режиме, в кинетике видны как быстрая, так и медленная компонента, что соответствует наблюдаемой спектральной картине. Постоянная времени затухания для экситонной люминесценции составляет порядка $1.1 \mathrm{~ns}$. В соответствии с литературными данными собственное время высвечивания для экситонной люминесценции составляет около $0.7 \mathrm{~ns}$. В данном случае более длительный спад регистрируется из-за того, что не учитывалась ширина рентгеновского импульса, которая составляла около $0.8 \mathrm{~ns}$.

Таким образом, в работе исследованы морфология, оптические и люминесцентные свойства ансамбля вискерных микрокристаллов оксида цинка на сапфире, полученных методом газофазного синтеза из элементов по механизму ПЖК. Электронно-микроскопические изображения демонстрируют присутствие двух типов одноосных микрокристаллов: гексагональные призмы и монокристаллические микростержни.

В спектре РЛ доминирующей является полоса экситонной люминесценции с максимумом на длине волны $388.3 \mathrm{~nm}$. Постоянная времени, полученная из кинетики РЛ, составила $1.1 \mathrm{~ns}$ без учета ширины возбуждающего импульса. Полное пропускание образца в видимой и ближней инфракрасной области не превышает 20\% при толщине слоя порядка $15-18 \mu \mathrm{m}$, что обусловлено большим количеством преломляющих поверхностей.

\section{Финансирование работы}

Работа проводилась с использованием оборудования ЦКП ФНИЦ „Кристаллография и фотоника“ при поддержке Министерства науки и высшего образования PФ (проект RFMEFI62119X0035) в рамках выполнения государственного задания ФНИЦ „Кристаллография и фотоника“ РАН (в части получения пленок), а также Российского фонда фундаментальных исследований (грант № 18-29-12099 мк - в части структурной диагностики и микроскопии эпитаксиальных пленок, грант № 18-52-76002 ЭРА_а - в части исследования люминесцентных и сцинтилляционных характеристик эпитаксиальных пленок).

\section{Конфликт интересов}

Авторы заявляют, что у них нет конфликта интересов.

\section{Список литературы}

[1] Wilkinson J., Ucer K.B., Williams R.T. // Nucl. Instr. Meth. Phys. Res. A. 2005. V. 537. P. 66-70.

[2] Родный П.А., Черненко К.А., Веневцев И.Д. // Оптика и спектроскопия. 2018. Т. 125. В. 3. С. 357-363. 
[3] Wagner M.R., Callsen G., Reparaz G.S., Schulze J.-H., Kirste R., Cobet M., Ostapenko I.A., Rodt S., Nenstiel C., Kaiser M., Hoffmann A., Rodina A.V., Phillips M.R., Lautenschläger S., Eisermann S., Meyer B.K. // Phys. Rev. B. 2011. V. 84. N 3. P. 035313.

[4] Meyer B.K., Alves H., Hofmann D.M., Kriegseis W., Forster D., Bertram F., Christen J., Hoffmann A., Straßurg M., Dworzak M., Haboeck U., Rodina A.V. // Phys. Status Solidi B. 2004. V. 241. N 2. P. 231-260.

[5] Oka K., Shibata H., Kashiwaya S. // J. Cryst. Growth. 2002. V. 237-239. Pt 1. P. 509-513.

[6] Huang F., Lin Z., Lin W., Zhang J., Ding K., Wang Y., Zheng $Q$., Zhan Z., Yan F., Chen D., Lv P., Wang X. // Chin. Sci. Bull. 2014. V. 59. N 12. P. 1235-1250.

[7] Горохова Е.И., Еронько С.Б., Орещенко Е.А., Сандуленко А.В., Родный П.А., Черненко К.А., Веневцев И.Д., Кульков A.M., Muktepavela F., Boutachkov P. // Опт. журн. 2018. T. 85. № 11. C. $90-100$.

[8] Venevtsev I.D., Rodnyi P.A., Muslimov A.E., Kanevskii V.M., Babaev V.A., Ismailov A.M. // Optics and Spectroscopy. 2019. V. 127. N 6. P. 1075.

[9] Ополченцев А.М., Задорожная Л.А., Брискина Ч.М., Маркушев В.М., Тарасов А.П., Муслимов А.Э., Каневский В.М. // Оптика и спектроскопия. 2018. Т. 125. В. 10. C. 501-506.

[10] Rodnyi P.A., Mikhrin S.B., Mishin A.N., Sidorenko A.V. // IEEE Trans. Nucl. Sci. 2001. V. 48. N 6. P. 2340-2343.

[11] Горохова Е.И., Родный П.А., Черненко К.А., Ананьева Г.В., Еронько С.Б., Орещенко Е.А., Ходюк И.В., Локшин Е.П., Куншина Г.Б., Громов О.Г., Лотт К.П. // Опт. журн. 2011. T. 78. № 11. C. 85-95. 